\title{
The Effects of Plant Growth Regulators On The Oil Content And Fatty Acid Composition of Ricinus Communis L.: An In Vitro Study
}

\author{
Zeynep Ergun ( $\nabla$ zergun@atu.edu.tr ) \\ Adana Alparslan Turkes Science and Technology University: Adana Alparslan Turkes Bilim ve Teknoloji Universitesi \\ https://orcid.org/0000-0002-9868-9488
}

\section{Research Article}

Keywords: Callus culture, fatty acids, plant growth regulators, Ricinus communis L.

Posted Date: July 29th, 2021

DOI: https://doi.org/10.21203/rs.3.rs-724779/v1

License: @ (i) This work is licensed under a Creative Commons Attribution 4.0 International License. Read Full License 


\section{Abstract}

This study aimed to investigate the effects of plant growth regulators in callus cell culture on the oil content and fatty acid composition of the castor bean (Ricinus communis L.). Ricinus communis L. are valued for its oil and the performance of oil is closely related to its fatty acid composition. Thus, producing oil in vitro with favored fatty acid profiles is a promising research area and may also offer industrial opportunities. In line with this, the total amount of fat and the fatty acid composition of the samples, which were endosperm and calli obtained by treatment of various doses of plant growth regulators were determined. Results showed that the type and amount of the plant growth regulator used in the media affect the fatty acid composition. In detail, the biggest change was shown by Indole-3-Acetic Acid (IAA), in general, using the plant growth regulators at $5 \mathrm{mgL}^{-1}$, instead of $20 \mathrm{mgL}^{-1}$, was found to have induced larger differentiations. The effect of a natural plant growth regulator (IAA) on fatty acid profiles was larger than the synthetic ones (NAA, 1Naphthaleneacetic acid, and 2,4 D, 2,4-Dichlorophenoxyacetic acid). The media containing $5 \mathrm{mgL}^{-1}$ of NAA, $20 \mathrm{mgL}^{-1}$ of NAA, $20 \mathrm{mgL}^{-1}$ of $2,4 \mathrm{D}$, or $5 \mathrm{mgL}^{-1}$ of $2,4 \mathrm{D}$ gave similar results.

\section{Introduction}

Earth is a plant-oriented planet and oil-bearing plants has special importance. Oil-bearing plants are also adding value of earth's plant diversity and fundamental to all life. They have been used as medicine for centuries [1-4].

As a member of the Euphorbiaceae family, Ricinus communis $\mathrm{L}$. is a toxic plant, and is also called the Castor bean. The origin of the Ricinus communis L. is believed to be Ethiopia and it has spread to the Middle East, India, and China.

Portuguese colonizers introduced the plant to the American continent. It can be found naturally in tropical, subtropical, and temperate areas in the world [5] and also the plant has been cultivated in some parts of the world. Turkey is one of the natural habitats of Ricinus communis $\mathrm{L}$.

Castor bean oil can be used in more than 700 fields, such as medicine, cosmetics, lubricants, plastics, and the manufacturing of biodiesel [6]. Traditional and modern medicine uses castor bean plant [7]. It has been used for its purgative-laxative, and contraceptive effects/abilities. It has a therapeutic use in cancer chemotherapy and with its high protein levels, de-oiled residue is utilized as a fertilizer [8]. High-quality biodiesel can be produced by using castor oil [913]. Moreover, it can be employed as an animal feed stuff after detoxification due to its high oil and protein content [14]. It is also used for ornamental purposes, the prolific growth in poor soils, and vibrant leaf and floral coloration make it favored [15]. Containing an unusual fatty acid called ricinoleic acid makes this plant important. The plant has high lubrication quality [16]. Moreover, the oil content of the Castor bean is high and ricinoleic acid is the dominant fatty acid. Castor seeds contain $50 \%$ oil on average and this percentage is quite high compared to the other oil seeds [17-20].

This high usage potential of castor oil has increased the Ricinus communis L. cultivation in many countries [21]. New genotypes of castor plants providing a high seed and oil yield have been developed [22]. Even though the interest in castor beans and their oil has increased, the production is relatively low regarding other the oilseed crops [22]. According to 2019 FAO data, from all over the world, castor seed oil was harvested from an area of 1.158.609 hectares and the total production was 1.407.588 metric tonnes. The major castor bean-producing countries were India, Mozambique, China, Brazil, Myanmar, and Ethiopia [23]. These six countries accounted for almost $97 \%$ of the world total produced castor beans. As the largest producer, India produced nearly $85 \%$ of the world's total.

Most of the uses of Ricinus communis L. are related to its oil, and the performance of the oil is closely related to the fatty acid composition. Therefore, the determination of the fatty acid composition of this plant is substantial importance.

Although in the literature there are many studies on the determination of oil content and fatty acid composition of various plants grown in field conditions [24-39]. However studies on the determination of fatty acid and oil content of explants 
obtained by plant cell culture applications are very rare [40-44].

Castor is a plant that has various usage areas; but a growing population, food shortages, and nutritional problems threaten the sustainability of its cultivation. Indeed, food must have a priority in the agricultural field. But this must lead to alternative oil production methods for non-food crops, such as castor beans. Plant cell culture is a promising way for the production of plants produced from these plants sustainable way. Plant cell culture techniques enable an effect on the oil amount and fatty acid compositions [40-44]. The number of studies focusing on the effect of plant regulators on fatty acid composition and oil content in callus culture [44-45] is insufficient. Moreover, the castor bean has not been studied in that manner.

In this study, the production of castor oil in vitro and the effects of plant growth regulator contents in the media on the fatty acid compositions were investigated. To the author's best knowledge, this is the first study that focuses on in vitro fatty acid composition manipulation by employing different plant growth regulators with varying amounts for Ricinus communis $\mathrm{L}$. The results are believed to contribute to the plant cell culture practices focusing on in vitro production of not only oil but also other primary and secondary metabolites.

\section{Materials And Methods}

\subsection{Plant material}

Health Ricinus communis L. seeds were collected in 2019 from the Çukurova University Ali Nihat Gökyiğit Botanical Garden, Adana/Turkey when the seeds were fully ripened.

\subsection{Media preparation and callus culture generation}

The homogenous seeds were washed under running tap water for 10 minutes. The seeds were surface-sterilized with a solution containing $20 \%$ sodium hypochlorite $(\mathrm{NaOCl})$ for 20 minutes while stirring and then rinsed with $70 \%$ ethanol for 1 minute. After this, the seeds were washed 5 times with sterile double-distilled water in a laminar flow cabinet. Murashige \& Skoog medium (MS) [46] (4.4 g/L) is used as the main nutrient medium for obtain callus. Calli were derived from seed cotyledons on solid an MS (4.4 g/L) medium supplemented with 2,4 D (Dichlorophenoxyacetic acid), IAA (Indoleacetic acid), NAA (naphthaleneacetic acid), 5-20 mg/L, and $30 \mathrm{~g} / \mathrm{L}$ fructose. A detailed depiction of the media contents can be found in Table 1. The $\mathrm{pH}$ was adjusted to 5.8 (using a $0.1 \mathrm{M} \mathrm{HCl}$ or $\mathrm{KOH}$ solution) before autoclaving at $121^{\circ} \mathrm{C}$ for 20 minutes. All cultures were incubated at $25 \pm 2{ }^{\circ} \mathrm{C}$ until the calli emerged under $16 / 8$ light/dark photoperiod. At the end of 120 days, the calli were collected from the media for oil extraction. The content of the media can be seen in Table 1.

Table 1. Detailed media contents

\begin{tabular}{lllllll} 
& Medium 1 & Medium 2 & Medium 3 & Medium 4 & Medium 5 & Medium 6 \\
\hline Agar $\left(\mathrm{gL}^{-1}\right)$ & 8 & 8 & 8 & 8 & 8 & 8 \\
\hline $\mathrm{MS}\left(\mathrm{gL}^{-1}\right)$ & 4.4 & 4.4 & 4.4 & 4.4 & 4.4 & 4.4 \\
\hline Fructose $\left(\mathrm{gL}^{-1}\right)$ & 30 & 30 & 30 & 30 & 30 & 30 \\
\hline $2,4 \mathrm{D}\left(\mathrm{mgL}^{-1}\right)$ & 5 & 0 & 0 & 20 & 0 & 0 \\
\hline $\mathrm{NAA}\left(\mathrm{mgL}^{-1}\right)$ & 0 & 0 & 5 & 0 & 20 & 0 \\
\hline IAA $\left(\mathrm{mgL}^{-1}\right)$ & 0 & 20 & 0 & 0 & 0 & 5
\end{tabular}


The extraction of the total lipids was done by an automatic soxhlet device. The solvent was hexane and extracted oil was weighed for the determination of the oil percentage in the samples.

\subsection{Determination of fatty acids}

Esterification of fatty acids was performed using the method described by Perdomo et al. [47]. One hundred $\mathrm{mL}$ of oil was mixed with $1 \mathrm{~mL}$ of $\mathrm{NaOH}$ methanolic solution. Samples were heated up to $100^{\circ} \mathrm{C}$ for 25 minutes, followed by adding 6 $\mathrm{mL}$ of $\mathrm{HCl}$ methanolic solution. After heating the obtained solvent up to $80^{\circ} \mathrm{C}$ for 10 minutes, $75 \mathrm{~mL}$ of equimolar hexane was added. The upper phase was removed and mixed with $9 \mathrm{~mL}$ of $\mathrm{NaOH}$ solution, and after 1 minute a standing solution was used for injection into the gas chromatography (GC, Perkin Elmer, Auto system GLX, Shelton, USA). Chromatographic separation was performed using a Supelco SPTM-2380 (30 m, $0.25 \mathrm{~mm}$ inner diameter, $0.25 \mathrm{~mm}$ film thickness) column equipped with a flame ionization detector (FID). The injector and detector temperatures were $280^{\circ} \mathrm{C}$ and $260^{\circ} \mathrm{C}$ respectively. The carrier gas was helium with a flow rate of $0.5 \mathrm{~mL} / \mathrm{min}$. The initial temperature of the oven was adjusted at $120^{\circ} \mathrm{C}$ for 2 minutes, increased at $58 \mathrm{C} / \mathrm{min}$ to $220^{\circ} \mathrm{C}$, and held there for 10 minutes. Data were collected and quantified with a TotalChrom Navigator and the results were expressed as percentage concentration [48]. The results were expressed in $\mathrm{GC}$ area \% as a mean value and \pm standard deviation.

\subsection{Statistical Analysis}

The Kruskal-Wallis H Test, the Cluster Analysis, and the Principal Component Analysis (PCA) were performed for the statistical analysis. The Kruskal-Wallis $\mathrm{H}$ test was used to see whether the distribution of the parameters (oil content and fatty acid composition) was the same or significantly different across the different media. The reason for choosing this method was the non-normal distribution characteristics of the observations. It is a nonparametric median comparison test. Additionally, for grouping the observations, hierarchical cluster analysis was performed. Ward's method was chosen as the linkage method. Dendrograms, which are outputs of hierarchical cluster analysis, enable us to see the groups. Thirdly, the Principal Component Analysis (PCA) was used to create the biplot graph. The biplot graph, an output of this analysis, is a practical tool for understanding and visualizing the interrelationships of observations and variables by generating a first principal component (PC1) and a second principal component (PC2). In biplots, the length of the lines shows the variances of the variables, with longer lines pointing to higher variances. The cosine of the angle and the lines show the correlation between the variables. In detail, the closer the angle to 90 or 270 degrees, the lower a correlation is being shown, and a correlation of 1 or -1 is approximated by an angle of 0 or 180 degrees. Finally, the distance between two points approximates the Euclidean distance between two observations in the multivariate space. Observations that are far away from each other have a high Euclidean distance, and vice versa [49]. The Kruskal-Wallis H Test and hierarchical cluster analysis were performed by using SPSS software and the PCA was performed through XLStat software.

\section{Results}

The total fat and fatty acid content of the endosperm and calli obtained by using various plant growth regulators with varying amounts are shown in Table 2. While the oil content of the endosperm was found to be $69.58 \mathrm{~g} / 100 \mathrm{~g}$, the oil content of the in vitro grown calli ranged from $0.37 \mathrm{~g} / 100 \mathrm{~g}$ to $20.89 \mathrm{~g} / 100 \mathrm{~g}$ and in descending order medium 4 (20.89 $\mathrm{g} / 100 \mathrm{~g})>$ medium $3(12.42 \mathrm{~g} / 100 \mathrm{~g})>$ medium $5(11.18 \mathrm{~g} / 100 \mathrm{~g})>$ medium $1(3.64 \mathrm{~g} / 100 \mathrm{~g})>$ medium $2(1.42 \mathrm{~g} / 100 \mathrm{~g})$,

and finally medium $6(0.37 \mathrm{~g} / 100 \mathrm{~g})$, respectively (Table 2). In this study, the main focus was investigating the effect of plant growth regulators on fatty acid compositions, rather than increasing the oil level in vitro. Therefore, it can be misleading to compare the calli and endosperm oil percentages. Moreover, the calli used for extraction were fresh and not dried. In these circumstances, the oil amount was expected to increase in line with the literature that shows the oil level can be increased by the plant cell culture techniques [50,51]. 
Table 2. Total oil and fatty acids content of the endosperm and calli were obtained by using various plant growth regulators with varying amounts

\begin{tabular}{|c|c|c|c|c|c|c|c|}
\hline & Endosperm & Medium 1 & Medium 2 & Medium 3 & Medium 4 & Medium 5 & Medium 6 \\
\hline Total fat & $69.58 \pm 0.01$ & $3.64 \pm 0.04$ & $1.42 \pm 0.01$ & $12.42 \pm 0.00$ & $20.89 \pm 0.06$ & $11.18 \pm 0.01$ & $0.37 \pm 0.01$ \\
\hline $\begin{array}{l}\text { Palmitic acid } \\
\text { (C16:0) }\end{array}$ & $4.07 \pm 0.08$ & $8.46 \pm 0.32$ & $13.69 \pm 0.01$ & $6.57 \pm 0.00$ & $5.88 \pm 0.05$ & $6.47 \pm 0.20$ & $18.46 \pm 0.03$ \\
\hline $\begin{array}{l}\text { Stearic acid } \\
(\mathrm{C} 18: 0)\end{array}$ & $4.47 \pm 0.04$ & $6.15 \pm 0.01$ & $9.16 \pm 0.07$ & $6.14 \pm 0.09$ & $5.44 \pm 0.00$ & $4.85 \pm 0.03$ & $6.03 \pm 0.21$ \\
\hline $\begin{array}{l}\text { Arachidic acid } \\
\text { (C20:0) }\end{array}$ & $0.13 \pm 0.00$ & $0.63 \pm 0.00$ & $0.39 \pm 0.00$ & $0.35 \pm 0.06$ & $0.45 \pm 0.00$ & $0.44 \pm 0.02$ & $0.00 \pm 0.00$ \\
\hline $\begin{array}{l}\text { Behenic acid } \\
\text { (C22:0) }\end{array}$ & $0.00 \pm 0.00$ & $0.36 \pm 0.04$ & $0.50 \pm 0.04$ & $0.15 \pm 0.04$ & $0.13 \pm 0.06$ & $0.18 \pm 0.01$ & $1.66 \pm 0.06$ \\
\hline$\Sigma$ SFA & $8.67 \pm 0.04$ & $15.23 \pm 0.33$ & $23.24 \pm 0.06$ & $13.06 \pm 0.15$ & $11.54 \pm 0.27$ & $\begin{array}{l}11.53 \pm \\
0.47\end{array}$ & $\begin{array}{l}26.15 \pm \\
0.24\end{array}$ \\
\hline $\begin{array}{l}\text { Oleic acid } \\
\text { (C18:1n9c)w-9 }\end{array}$ & $\begin{array}{l}11.75 \pm \\
0.02\end{array}$ & $17.46 \pm 0.04$ & $22.99 \pm 0.13$ & $19.65 \pm 0.04$ & $\begin{array}{l}17.74 \pm \\
0.06\end{array}$ & $\begin{array}{l}19.86 \pm \\
0.01\end{array}$ & $\begin{array}{l}21.65 \pm \\
0.11\end{array}$ \\
\hline $\begin{array}{l}\text { cis-11- } \\
\text { Eicosenoic } \\
\text { acid (C20:1) }\end{array}$ & $1.12 \pm 0.05$ & $1.51 \pm 0.00$ & $1.79 \pm 0.10$ & $1.53 \pm 0.02$ & $1.53 \pm 0.04$ & $1.69 \pm 0.04$ & $\begin{array}{l}19.81 \pm \\
0.67\end{array}$ \\
\hline $\begin{array}{l}\text { Ricinoleic acid } \\
{[\mathrm{C} 18: 1(\mathrm{OH})]}\end{array}$ & $\begin{array}{l}51.17 \pm \\
0.31\end{array}$ & $36.41 \pm 0.53$ & $29.17 \pm 0.28$ & $\begin{array}{l}39.88 \pm \\
0.42\end{array}$ & $\begin{array}{l}42.21 \pm \\
0.15\end{array}$ & $\begin{array}{l}39.61 \pm \\
0.06\end{array}$ & $4.73 \pm 0.27$ \\
\hline$\Sigma$ MUFA & $\begin{array}{l}64.03 \pm \\
0.24\end{array}$ & $55.38 \pm 0.49$ & $53.95 \pm 0.51$ & $\begin{array}{l}61.05 \pm \\
0.43\end{array}$ & $\begin{array}{l}61.47 \pm \\
0.05\end{array}$ & $\begin{array}{l}61.15 \pm \\
0.08\end{array}$ & $\begin{array}{l}46.18 \pm \\
0.30\end{array}$ \\
\hline $\begin{array}{l}\text { Linoleic acid } \\
\text { (Cl8:2n6c) } \omega-6\end{array}$ & $\begin{array}{l}18.05 \pm \\
0.08\end{array}$ & $14.83 \pm 0.19$ & $4.26 \pm 0.07$ & $\begin{array}{l}12.52 \pm \\
0.23\end{array}$ & $\begin{array}{l}14.77 \pm \\
0.13\end{array}$ & $\begin{array}{l}14.41 \pm \\
0.12\end{array}$ & $6.43 \pm 0.37$ \\
\hline $\begin{array}{l}\text { a-Linolenic } \\
\text { acid (C18:3n3) } \\
\omega-3\end{array}$ & $1.47 \pm 0.08$ & $2.36 \pm 0.03$ & $0.00 \pm 0.00$ & $0.73 \pm 0.12$ & $0.98 \pm 0.04$ & $1.39 \pm 0.04$ & $3.59 \pm 0.15$ \\
\hline$\Sigma$ PUFA & $\begin{array}{l}19.52 \pm \\
0.17\end{array}$ & $17.19 \pm 0.16$ & $4.26 \pm 0.07$ & $\begin{array}{l}13.25 \pm \\
0.35\end{array}$ & $\begin{array}{l}15.74 \pm \\
0.09\end{array}$ & $\begin{array}{l}15.79 \pm \\
0.08\end{array}$ & $\begin{array}{l}10.02 \pm \\
0.52\end{array}$ \\
\hline
\end{tabular}

Monounsaturated fatty acids (MUFA) was dominant both for the endosperm and the in vitro samples. The MUFA levels of calli ranged from $46.18 \%$ (medium 6 ) to $61.47 \%$ (medium 4). The dominant individual fatty acid was ricinoleic acid [C18:1(OH)] for all medium except medium 6. Different growth mediums produced diverse fatty acids. For example palmitic acid was the highest in medium $6 /$ medium 4 , stearic acid was the highest in medium $2 /$ medium 5 , arachidic acid was the highest in medium 2 /medium 6, oleic acid was the highest in medium 1/medium 2, cis-11-eicosenoic acid was the highest in medium 6/medium 3-4, ricinoleic acid was the highest in medium 4/medium 6 and linoleic acid was the highest in medium 1 /medium 2 (Table 2)

The changes of the fatty acids stemming from using various plant growth regulators with varying amounts in vitro can be seen in Fig. 1 in comparison with the endosperm oil. In vitro production mainly increased the SFAs and MUFAs (except ricinoleic acid, due to the change in proportion of ricinoleic acid, total MUFAs decreased). Additionally, it decreased the PUFAs, again with some small exceptions.

The Kruskal-Wallis Test and pairwise comparison (as the post hoc tests) results of total oil content and fatty acids can be seen in Table 3. The oil content of calli obtained by using medium 6 significantly differed from medium 2 and from 
endosperm. In detail, medium 2 and endosperm contained statistically significant larger amounts of oil when compared to the oil content of calli obtained by utilizing medium 6 . The level of palmitic acid was significantly larger in the output of medium 6 in comparison with endosperm in medium 2. The unique and significant differences in stearic, oleic, and linoleic acids were observed between the endosperm and medium 2 oils. Although medium 2 oils contained significantly more stearic and oleic acids than the endosperm oil, the endosperm oil contained a significantly larger amount of linoleic acid. In terms of arachidic acid, the amount was significantly greater in the medium 2 oil than in the endosperm and medium 6 oils. The medium 6 oil contained a significantly larger amount of cis-eicosenoic acid than the endosperm oil, and alinolenic acid than the medium 2 oil. As the dominant and possibly most important fatty acid of Ricinus communis L., ricinoleic acid was found in significantly less quantities in the endosperm and medium 2 oils in comparison with the medium 6 oil.

Table 3. Hypothesis test summary of independent-samples kruskal-wallis test and pairwise comparison results of total oil

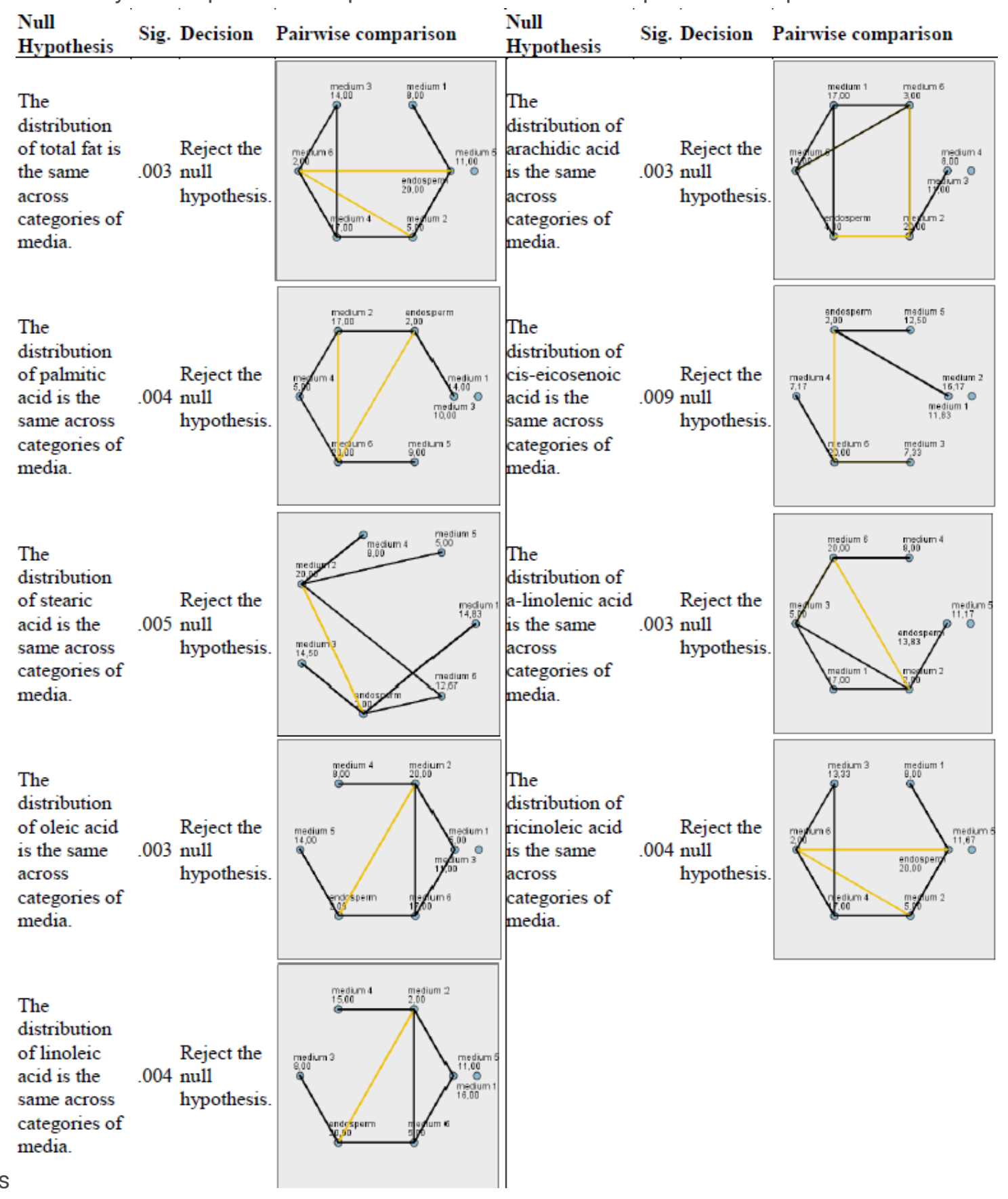

content and fatty acids 
Graphical representation of Dunn-Bonferroni's nonparametric pairwise comparison is for post hoc testing after a significant Kruskal-Wallis test.

Numerical values represent the mean rank of each group in the figures. Yellow lines represent statistically significant $(p<0.05)$ comparisons between the groups they connect. Black lines represent nonsignificant $(p \geq 0.05)$ comparisons between the groups they connect.

According to the hierarchical cluster analysis given in Fig. 2, the fatty acid compositions of Ricinus communis $\mathrm{L}$. endosperm oil and oil obtained by using various media were grouped by means of their similarities. The most similar oil profiles were observed in the oils of medium3, medium 5 , medium 4 and medium 1 . At this stage, the other oils created individual groups. If the rest of the observations were ranked from the most similar to least similar, it can be listed as endosperm oil, medium 2 oil and medium 6 oil, respectively. In detail, the media that contained $5 \mathrm{mgL}^{-1} \mathrm{of} \mathrm{NAA}_{2} 20 \mathrm{mgL}^{-1}$ of NAA, $20 \mathrm{mgL}^{-1}$ of $2,4 \mathrm{D}$, and $5 \mathrm{mgL}^{-1}$ of $2,4 \mathrm{D}$ created a group. Medium 2 and medium 6 , which contained $20 \mathrm{mgL}^{-1}$ and $5 \mathrm{mgL}^{-1}$ of IAA, deviated from the group.

According to the PCA results of the fatty acid composition of Ricinus communis L. (Figure, 3), endosperm oil and oil produced by using media which contain various plant growth regulators at various amounts, PC1 and PC2 could explain $57.75 \%$ and $35.19 \%$ of the total variance, respectively. Thus, $92.93 \%$ of the total variance was able to be explained by the first two principal components. In terms of Euclidean distance, the grouping, showed by the circles, supported the results of the cluster analysis. The largest amounts of linoleic acid were observed in endosperm. On the other hand, endosperm contained the smallest amounts of palmitic, stearic, oleic and cis-11-eicosenoic acids. The largest amounts of stearic acid, oleic acid, and arachidic acid were observed in oil of medium 2, while it contained the smallest linoleic acid levels and no a-linolenic acid. The largest levels of palmitic, cis-eicosenoic, and a-linolenic acid were found in the medium 6 sample, however the lowest levels of arachidic acid and ricinoleic acid were detected in this sample.

\section{Discussion}

The products of plant cells can be grouped as primary and secondary metabolites [50]. In the literature, although there are studies that investigate the production of primary and secondary metabolites in vitro [43, 50-53], this number of studies is insufficient. Among the primary metabolites, this study focused on fatty acid composition manipulation through plant cell culture techniques by looking at the effects of plant growth regulators.

It was observed that when 2,4 D was employed as the plant growth regulator with $5 \mathrm{mgL}^{-1}$, the oil percentage was $3.64 \%$, but was $20.89 \%$ if the plant growth regulator increased to $20 \mathrm{mgL}^{-1}$. When NAA and IAA were used with $5 \mathrm{mgL}^{-1}$, the oil percentages were $11.18 \%$ and $0.37 \%$, but when they were added to $20 \mathrm{mgL}^{-1}$, the oil percentages increased to $12.42 \%$ and $1.42 \%$, respectively. This may lead to a conclusion that if the amount of the plant growth regulator increases in the medium, the oil content also increases.

Previous studies have revealed that the fatty acid profiles and amount of oil differs among seeds [43, 54]. In line with this, the results of this study are supported by the literature. The largest decrease was detected in ricinoleic acid levels, especially in medium 6. As seen in Fig. 1, the biggest increases and decreases were detected in the medium 6 and medium 2 samples, which contained $5 \mathrm{mgL}^{-1}$ and $20 \mathrm{mgL}^{-1}$ of IAA. IAA is the sole natural plant growth regulator used in this research, in line with this, it can also be claimed that the effect of naturel plant growth regulators was more effective than the synthetic ones. Another important result is that, from a general point of view, the fatty acids of the samples grown in the media that contained the same plant growth regulator, but in lesser amounts, created larger changes.

Previous studies proved that by in vitro production of the oils, some new fatty acids may emerge, or some of them may disappear, in comparison with the seeds [54]. Similarly, in this investigation, some of the fatty acids that were not detected 
in the endosperm sample such as erusic, lauric, and myristic acids were found in calli. Additionally, a-linolenic acid was found in endosperm but it disappeared in calli.

These results indicate that manipulating the growth regulators in the induction media influenced the fatty acids synthesis and hence the fatty acids profile in Castor bean calli grown in vitro. It is well known that phytohormones are chemical messengers involved in a broad spectrum of physiological and biochemical processes of higher plants at very low concentrations. Therefore, the regulation of the biosynthesis of oil and fatty acids in Castor bean with phytohormones supplemented for the harvest of more high-value products like oil and fatty acids are promising. There are several reports on the substantial influence of plant growth regulators such as auxin (2,4-D) and cytokinin (BA) on plant lipid composition and lipid metabolism in terms of fatty acids induction and alteration of their composition specifically the alterations of both the ratios of $\mathrm{C} 18: 2$ to $\mathrm{C} 18: 1$ and $\mathrm{C} 18: 3$ to $\mathrm{C} 18: 2$ [55-56]

\section{Conclusions}

The results of the present research revealed that fatty acid composition of the in vitro produced oils can be manipulated by using different plant growth regulators with varying the amounts in the media. Producing the oil in vitro increased the saturated fatty acids and monounsaturated fatty acids. But due to the larger decrease in the ricinoleic acid, the total monounsaturated fatty acids decreased. Polyunsaturated fatty acids were also found to have decreased with some exceptions. The biggest change was detected in ricinoleic acid. Moreover, the largest changes were observed in the samples obtained by using the media that contain $5 \mathrm{mgL}^{-1}$ and $20 \mathrm{mgL}^{-1}$ of IAA as the plant growth regulator. It also has been found that using the plant growth regulators at higher levels did not stimulate higher levels of the fatty acids, although higher levels of these fatty acids were detected in the samples obtained from the media which contained lower levels of these plant growth regulators. Finally, the fatty acid compositions of the samples grown in the media that contained 2,4 D and NAA were more similar to other media that contained IAA. As further research recommendations, an investigation on the optimal level of plant growth regulators can be done by increasing the numbers of plant growth regulators and by using other plants. Other techniques to inflate the total amount of oil, such as bioreactors, should be taken into consideration for mass production of manipulated fatty acids independent from the availability of seeds, agricultural territories, climate, etc.

\section{Declarations}

Acknowledgments: The author is thankful to the academic and administrative staff of Çukurova University Ali Nihat Gökyiğit Botanical Garden for the materials used in this study.

Funding: No external funding obtained for this project.

Availability of data and materials: The datasets generated during and/or analyzed during the current study are available from the corresponding author on reasonable request.

Conflicts of Interest: The authors declare that they have no conflict of interest.

Research involving human and/or animal participants: This article does not contain any studies with human or animal subjects.

\section{Compliance with Ethical Standards}

Ethical approval: None

\section{References}


1. Maras-Vanlioglu F.G, Yaman H, Kayacetin F (2020) Genetic diversity analysis of some species in Brassicaceae family with ISSR markers. Biotech Studies 29:38-46.

2. Mollova S, Fidan H, Antonova D, Bozhilov D, Stanev S, Kostova I, Stoyanova A (2020) Chemical composition and antimicrobial and antioxidant activity of Helichrysum italicum (Roth) G. Don subspecies essential oils. Turk J Agric For 44 : 371-378.

3. Subasi I (2020) Seed fatty acid compositions and chemotaxonomy of wild Crambe (Brassicaceae) taxa in Turkey. Turk J Agric For 44: 662-670

4. Erdemir A (2021) Anti-proliferative and apoptosis inducing activity of Calophyllum inophyllum L. oil extracts on C6 glioma cell line. Biotech Studies 30:1-6.

5. Yusuf AK, Mamza PAP, Ahmed AS, Agunwa U (2015) Extraction and characterization of castor seed oil from wild Ricinus communis Linn. Int J Sci Environ 4 (5): 1392-1404.

6. Fadhil AB, Al-Tikrity ETB, Albadree MA (2017) Biodiesel production from mixed non-edible oils, castor seed oil and waste fish oil. Fuel 210: 721-728.

7. Scarpa A, Guerci A (1982) Various uses of the castor oil plant (Ricinus communis L.) a Review. J Ethnopharmacol 5 (2):117-137.

8. Akande TO, Odunsi AA, Akinfala EO (2016) A review of nutritional and toxicological implications of castor bean (Ricinus communis L.) meal in animal feeding systems. J Anim Physiol Anim Nutr 1: 201-210.

9. Arunkumar M, Kannan M, Murali G (2019) Experimental studies on engine performance and emission characteristics using castor biodiesel as fuel in $\mathrm{Cl}$ engine. Renew Energy 131: 737-744.

10. Zuleta EC, Rios LA, Benjumea PN (2012) Oxidative stability and cold flow behavior of Palm, Sacha-inchi, Jatropha and Castor oil biodiesel blends. Fuel Process Technol 102: 96-11. Islam MS, Ahmed AS, Islam A, Abdul Aziz S, Xian LC, Mridha M (2014) Study on emission and performance of diesel engine using castor biodiesel. J Chem 2014:451526.

12. Bueno AV, Pereira MPB, de Oliveira Pontes JV, de Luna FMT, Cavalcante CL (2017) Performance and emissions characteristics of castor oil biodiesel fuel blends. Appl Therm Eng 125: 559-566.

13. Jeong GT, Park DH (2009) Optimization of biodiesel production from castor oil using response surface methodology. Appl Biochem Biotechnol 156: 1-11.

14. Nicory IMC, de Carvalho GGP, Ribeiro OL, Silva RR. Tosto MSL, Costa-Lopes LS, Souza FNC, de Oliveira Nascimento C (2015) Ingestive behavior of lambs fed diets containing castor seed meal. Trop Anim Health Prod 47 (5): $939-944$.

15. Foster JT, Allan GJ, Chan AP, Rabinowicz PD, Ravel J, Jackson PJ, Keim P (2010) Single nucleotide polymorphisms for assessing genetic diversity in castor bean (Ricinus communis). BMC Plant Biol 10 (1): 13.

16. Yousaf MM, Hussain M, Shah MJ, Ahmed B, Zeshan M, Raza MM, Ali K (2018) Yield response of castor (Ricinus communis L.) to NPK fertilizers under arid climatic conditions. Pak J Agric Res 31 (2): 180-185.

17. Arif M, Khurshid H, Siddiqui SU, Jatoi SA, Jan SA, llyas M, Khan SA, Khan A, Ibrahim MI, Saleem N, Ghafoor A (2015) Estimating spatial population structure through quantification of oil content and phenotypic diversity in Pakistani castor bean (Ricinus communis L.) germplasm. Sci Technol Dev 34 (3): 147-154. 
18. Ruiz Olivares A, Carrillo-González R, González-Chávez M del CA, Soto Hernández R M (2013) Potential of Castor bean (Ricinus communis I.) for phytoremediation of mine tailings and oil production. J Environ Manage 114: 316-323.

19. Román-Figueroa C, Cea M, Paneque M, González ME (2020) Oil content and fatty acid composition in Castor bean naturalized accessions under Mediterranean conditions in Chile. Agronomy 10 (8): 1145.

20. Abolfazl A, Nasrin F, Habib S, Saeid H (2011) The effect of climatic factors on the production and quality of castor oil. Nat Sci 9 (4): 15-19.

21. Muraguri S, Xu W, Chapman M, Muchugi A, Oluwaniyi A, Oyebanji O, Liu A (2020) Intraspecific variation within Castor bean (Ricinus communis I.) based on chloroplast genomes. Ind Crops Prod 155: 112779.

22. Koutroubas SD, Papakosta DK, Doitsinis A (1999) Adaptation and yielding ability of Castor plant (Ricinus communis I.) genotypes in a Mediterranean climate. Eur J Agron 11 (3-4): 227-237.

23. FAO. Food and agricultural organization.

24. Rodríguez-Leyes EA, Canavaciolo VLG, Delange DM, Enríquez ARS, Fajardo YA (2007) Fatty acid composition and oil yield in fruits of five Arecaceae species grown in Cuba. J Am Oil Chem Soc 84 (8): 765-767.

25. Ergun Z, Bozkurt T (2020) Determination of fatty acid composition and antioxidant activity of fig seed oil. Int J Agric Nat Sci 13 (2): 101-107.

26. Zarifikhosroshahi M, Ergun Z (2021) The effect of storage temperature on the composition of fatty acids in crimson sweet (Citrullus lanatus var. lanatus) watermelon cultivar seeds. J Inst Sci Technol 11 (2): 839-845.

27. Ilhan G, Gundogdu M, Karlović K, Židovec V, Vokurka A, Ercisli S (2021) Main agro-morphological and biochemical berry characteristics of wild-grown sea buckthorn (Hippophae rhamnoides L. ssp. Caucasica Rousi) genotypes in Turkey. Sustainability 13 (3):1198.

28. Beyhan O, Ozcan A, Ozcan H, Kafkas E, Kafkas S, Sutyemez M, Ercisli S (2017) Fat, fatty acids and tocopherol content of several walnut genotypes. Not Bot Horti Agrobot Cluj-Napoca 45 (2): 437-441.

29. Ercisli S, Orhan E (2008) Fatty acid composition of seeds of yellow, red, and black colored Prunus mahaleb fruits in Turkey. Chem Nat Compd 44 (1): 87-89.

30. Binder RG, Applewhite TH, Kohler GO, Goldblatt LA (1962) Chromatographie analysis of seed oils. fatty acid composition of Castor oil. J Am Oil Chem Soc 39 (12); 513-517.

31. Canoira L, García Galeán J, Alcántara R, Lapuerta M, García-Contreras R. Fatty acid methyl esters (FAMEs) from Castor oil: Production process assessment and synergistic effects in its properties. Renew Energy 35 (1): 208-217.

32. Salimon J, Mohd Noor DA, Nazrizawati AT, Mohd Firdaus MY, Noraishah A (2010) Fatty acid composition and physicochemical properties of Malaysian Castor bean Ricinus communis L. seed oil. Sains Malays 39 (5): $761-764$.

33. Sreenivasan B, Kamath NR, Kane JG. Studies on Castor oil (1956) I. Fatty acid composition of Castor oil. J Am Oil Chem Soc 33 (2): 61-66.

34. Ercisli S, Agar G, Orhan E, Yildirim N, Hizarci Y (2007) Interspecific variability of rapd and fatty acid composition of some pomegranate cultivars (Punica granatum L.) growing in Southern Anatolia Region in Turkey. Biochem Syst Ecol 35 (11): 764-769. 
35. Serce S, Ercisli S, Sengul M, Gunduz K, Orhan E (2010) Antioxidant activities and fatty acid composition of wild grown Myrtle (Myrtus communis L.) fruits. Pharmacogn Mag 6 (21): 9-12.

36. Guney M, Oz AT, Kafkas E (2015) Comparison of lipids, fatty acids and volatile compounds of various kumquat species using HS/GC/MS/FID techniques. J Sci Food Agric 95 (6): 1268-1273.

37. Guney M (2020) Determination of fatty acid profile and antioxidant activity of rosehip seeds from Turkey. Int J Agric Environ Food Sci 4 (1): 81-86.

38. Ilyasoğlu H (2014) Characterization of rosehip (Rosa canina L.) seed and seed oil. Int J Food Prop 17 (7): $1591-1598$.

39. Stearns EM, Morton WT (1975) Biosynthesis of fatty acids from acetate in soybean suspension cultures. Lipids 10 (10): 597-601.

40. Stearns EM, Morton WT (1975) Effects of growth regulators on fatty acids of soybean suspension cultures. Phytochemistry 14 (3): 619-622.

41. Hafez RM, Mohammed AAY, El-Naby AERMA, Tolba AEA, Khalifa EYM, Hamed H M, Abdullah MMK, Ahmed MMF, Hekal MS, Ali DHA (2019) Changes in the profiling of fatty acids of Glycine max L. (Soybean) callus after mutagen treatments. Egypt J Bot 59 (3): 679-694.

42. Koufan M, Belkoura I, Mazri MA, Amarraque A, Essatte A, Elhorri H, Zaddoug F, Alaoui T (2020) Determination of antioxidant activity, total phenolics and fatty acids in essential oils and other extracts from callus culture, seeds and leaves of Argania spinosa (L.) skeels. Plant Cell Tissue Organ Cult 141 (1): 217-227.

43. Hernandez LR, Mendiola MAR, Castro CA, Gutiérrez-Miceli FA (2015) Effect of plant growth regulators on fatty acids composition in Jatropha curcas L. callus culture. J Oleo Sci 64 (3): 325-330.

44. Aly MAM, Amer EA, Al-Zayadneh WA, Eldin AEN (2008) Growth regulators influence the fatty acid profiles of in vitro induced Jojoba somatic embryos. Plant Cell Tissue Organ Cult 93 (1): 107-114.

45. Murashige T, Skoog FA (1962) Revised medium for rapid growth and bioassays with tobacco tissue cultures. Physiol Plant 15 (3): 473-497.

46. Perdomo FA, Acosta-Osorio AA, Herrera G, Vasco-Leal JF, Mosquera-Artamonov JD, Millan-Malo B, Rodriguez-Garcia ME (2013) Physicochemical characterization of seven Mexican Ricinus communis L. seeds \& oil contents. Biomass Bioenerg 48: 17-24.

47. Demirtas I, Pelvan E, Ozdemir IS, Alasalvar C, Ertas E (2013) Lipid characteristics and phenolics of native grape seed oils grown in Turkey. Eur J Lipid Sci Technol 115 (6): 641-647.

48. Kohler U, Luniak M (2005) Data Inspection Using Biplots. Stata J 5 (2): 208-223.

49. Dabuwar Benjamin E, Adamu Ishaku G, Andrew Peingurta F, Samuel Afolabi A (2019) Callus culture for the production of therapeutic compounds. Am J Plant Biol 4 (4): 76-84.

50. Aftab F, Akram S, Iqbal J (2008) Estimation of fixed oils from various explants and in vitro callus cultures of Jojoba (Simmondsia chinensis). Pak J Bot 40 (4): 1467-1471.

51. Murthy HN, Lee EJ, Paek KY (2014) Production of secondary metabolites from cell and organ cultures: strategies and approaches for biomass improvement and metabolite accumulation. Plant Cell Tissue Organ Cult 16: 1-16.

Page $11 / 14$ 
52. Dörnenburg H, Knorr D (1995) Strategies for the improvement of secondary metabolite production in plant cell cultures. Enzyme Microb Technol 1: 674-684.

53. da Luz Costa J, da Silva ALL, Bier MCJ, Brondani GE, Gollo AL, Letti LAJ, Erasmo E AL, Soccol CR (2015) Callus growth kinetics of physic nut (Jatropha curcas I.) and content of fatty acids from crude oil obtained in vitro. Appl Biochem Biotechnol 176 (3): 892-902.

54.Liu JY, Qiu W, Song YM (2016) Stimulatory effect of auxins on the growth and lipid productivity of Clorella pyrenoidosa and Scenedesmus quadricauda. Algal Res 18:273-280.

55. Park HY, Saini RK, Gopal J, Keum Y-S, Kim DH, Lee O, Sivanesan I (2017) Micropropagation and subsequent enrichment of carotenoids, fatty acids, and tocopherol contents in Sedum dasyphyllum L. Front Chem 5:77.

\section{Figures}

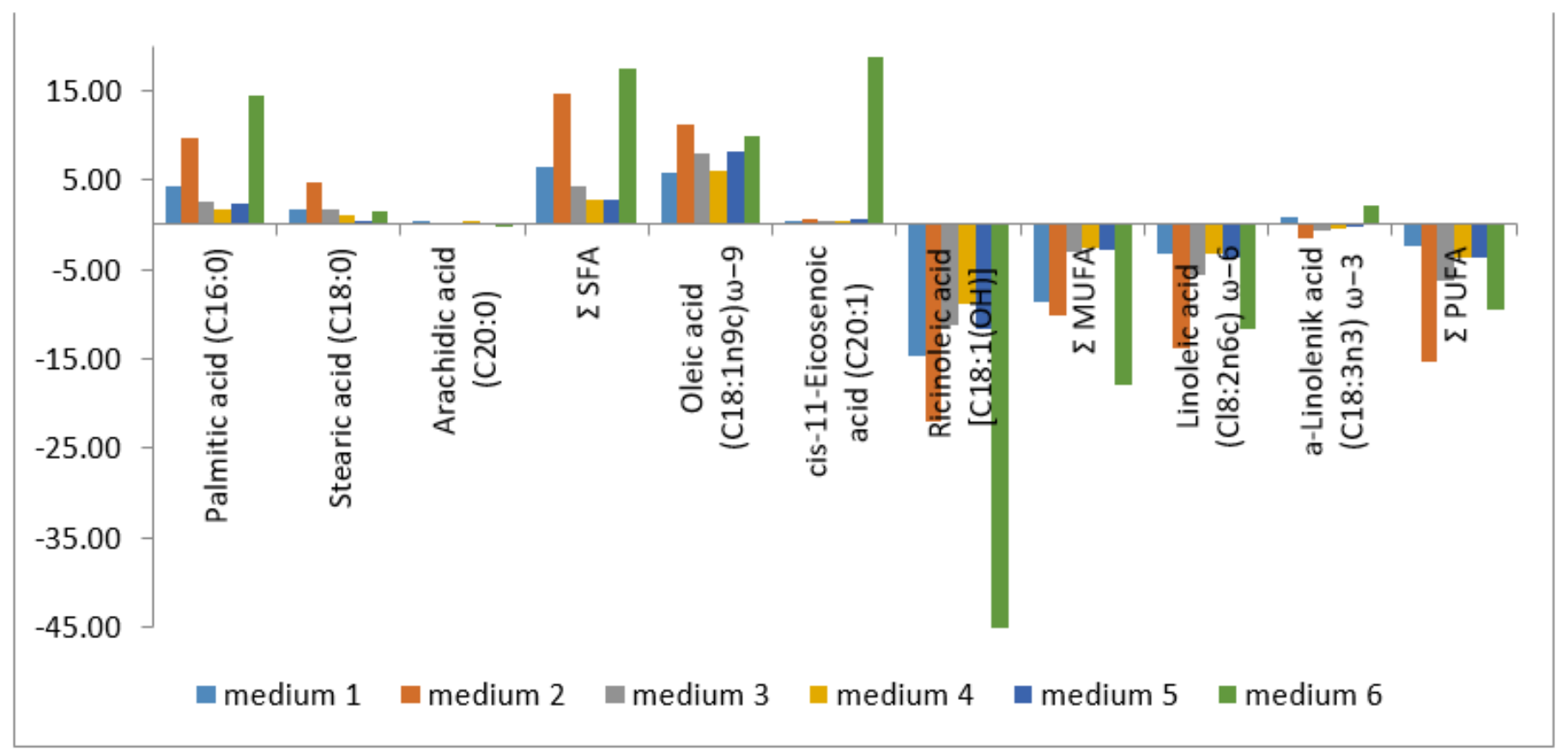

\section{Figure 1}

Graphical demonstration of the changes in the fatty acids of the in vitro material (\%) in comparison with the endosperm. 


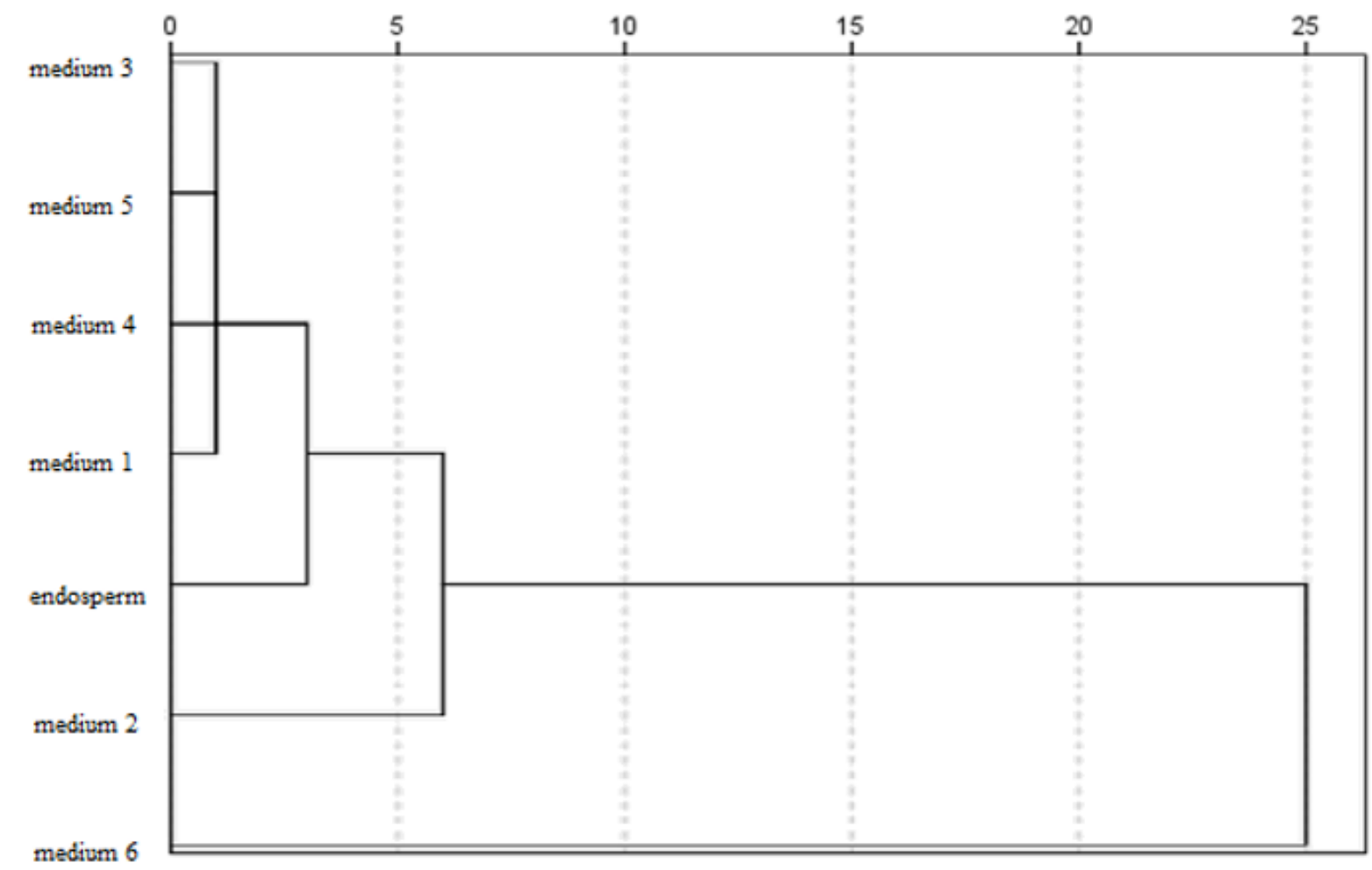

Figure 2

Hierarchical cluster analysis result (dendrogram using ward linkage, rescaled distance cluster combined)

Biplot (axes F1 and F2: 92,93\%)

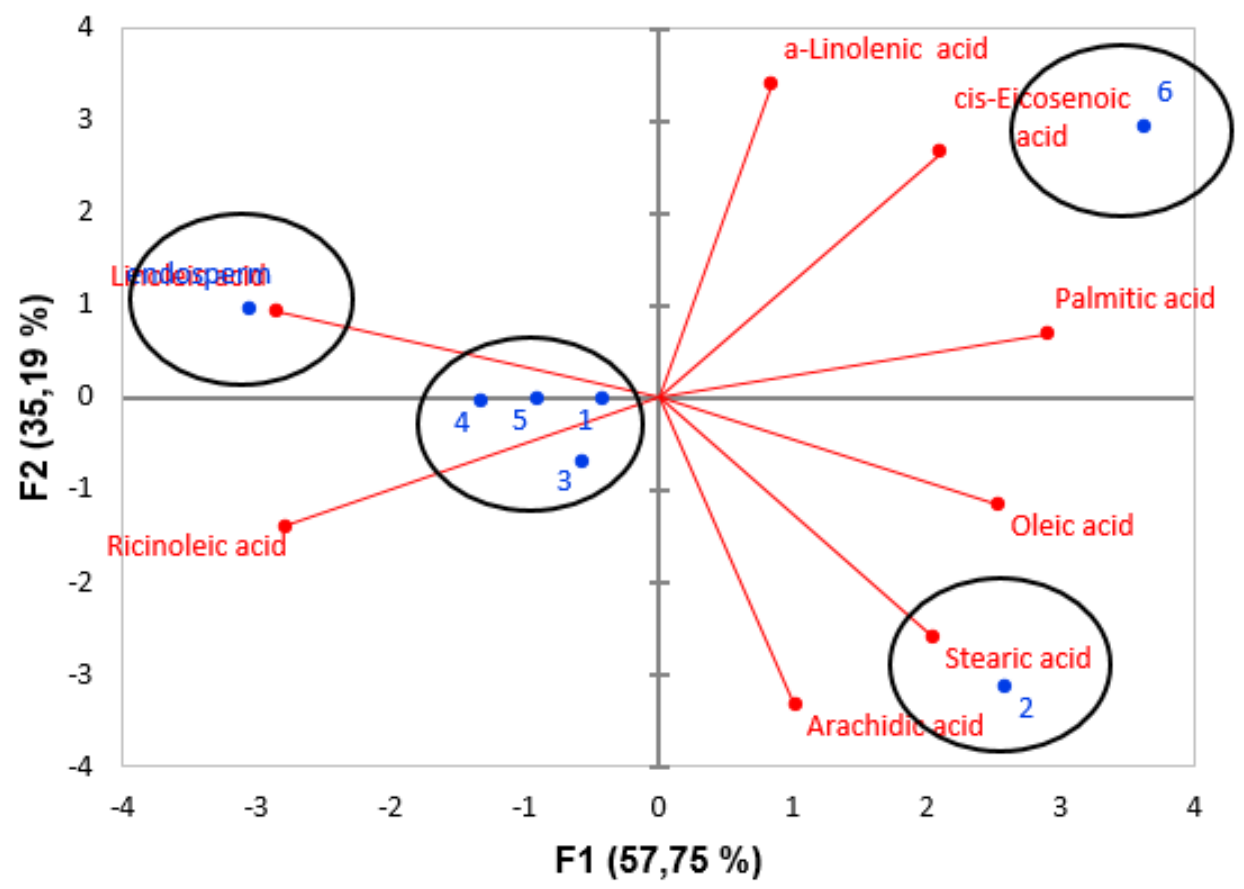

- Active variables - Active observations

Figure 3 
Biplot graph of fatty acids of the samples (scores and loading plots) obtained from Principal Component Analysis. (Abbreviations; 1: medium 1, 2: medium 2, 3: medium 3, 4: medium 4, 5: medium 5, 6: medium 6) 